\title{
OPTIMIZATION OF SOLID-LIQUID EXTRACTION OF ETHANOL OBTAINED BY SOLID-STATE FERMENTATION OF SURGARCANE BAGASSE
}

\author{
N.I. CANABARRO ${ }^{1}$, C. ALESSIO ${ }^{1}$, J.F. SOARES ${ }^{1}$, J.V.S. CORRÊA ${ }^{1}$, N. SUSIN ${ }^{1}$, W. \\ PRIAMO$^{2}$ e M.A. MAZUTTI ${ }^{1}$ \\ ${ }^{1}$ Universidade Federal de Santa Maria, Departamento de Engenharia Química \\ ${ }^{2}$ Departmento de Tecnologia de Alimentos, IFRS - Campus Sertão \\ E-mail para contato: claudianp@msn.com
}

\begin{abstract}
Solid-state fermentation has arrived as an alternative to reduce the amount of waste water in ethanol fermentation. However, the recovery of ethanol from solid medium should be investigated, since depending of experimental condition used in the extraction, significant difference in the results can be obtained. In this work was investigated the influence of temperature $\left(30-50^{\circ} \mathrm{C}\right)$, solid to liquid ratio $(0.1-0.4 \mathrm{wt} \%)$ and orbital agitation (50-180 rpm) in the recovery of ethanol from sugarcane bagasse at different fermentation conditions of moisture content (50-80\%) and ethanol amount $(5-20 \mathrm{wt} \%)$. The highest recovering efficiency was $99,8 \%$ at $30^{\circ} \mathrm{C}$, initial ethanol amount of $10 \mathrm{wt} \%$, orbital agitation of $100 \mathrm{rpm}$ and moisture content of $60 \%$. The main contribution of this work was to demonstrate that the amount of water used in the extraction is lesser than that used in traditional liquid fermentation, making possible to obtain a more concentrated broth, saving with water treatment and energy.
\end{abstract}

\section{INTRODUCTION}

Brazil is known as the greatest sugarcane producer in the worldwide, which is the basis for ethanol production. In recent years, the efforts in research and development have been directed toward reducing the input energy and cost for production of bioethanol as the most promising biofuel according Moukamnerd et al (2010).

For practical production, the total energy balance throughout the entire process including the pre- and post-fermentation must be considered, because biomass transportation of biomass and waste water treatment, respectively, require much energy, cited by Luo et al. (2009). Most of the conventional ethanol production methods involve liquid fermentation and exhaustion of fermentation broth and residue, mentioned by Sree et al. (1999), which require large amounts of energy and cost for treatment. In addition, because the water content of fermentation residues is high, a considerable amount of energy is required to dry them before incinerating or recycling them as fertilizers, according to Jain et al. (2013).

To reduce the amount of waste water in ethanol fermentation, solid-state fermentation (SSF) is one of the preferable options. In the process of bread dough where the water content is about $50 \%$, it is known that yeast is quite active and produce ethanol and carbon dioxide. The application of solid-state fermentation for ethanol production from biomass, however, 
requires the regulation of sugar and ethanol contents in the fermentation mixture below suitable levels because the high osmotic pressure and high ethanol content can decrease the fermentative activity of yeast, like the studies of Moukamnerd et al. (2010). In addition, SSF presents potential advantages such as: smaller volumes of fermentation mash, less requirement of water, physical energy requirement, among others.

In recent years, some researches were published focusing the ethanol production by solid-state fermentation. The researchers Lin et al. (2013) evaluated the production of ethanol from sugarcane bagasse by simultaneous saccharification and fermentation using a pilot rotary drum reactor (capacity of 100L). These authors demonstrated that the performance and the chosen SSF operating conditions for the drum reactor scale-up was as effective as those attained from flask runs and the use of rotary drum reactor for cellulosic ethanol production under SSF operating conditions is simple to scale up and shows commercial potential. Chu et al. (2012) employed solid-state fermentation of enzymatic hydrolysis residue and available to enhance ethanol production and cellulose-to-ethanol conversion. Kwon et al. (2011) and Yu et al. (2008) studied the ethanol production using sweet sorghum by solid-state fermentation. Moukamnerd et al. (2010) developed a consolidated continuous solid-state fermentation system for ethanol production by simultaneous saccharification and fermentation of raw corn starch. Wang et al. (2010) developed and validated a model of a rotating drum bioreactor with capacity of $5 \mathrm{~m}^{3}$ for ethanol production by solid-state fermentation. Sree et al. (1999) used solid substrate fermentation to produce ethanol from various starchy substrates like sweet sorghum, sweet potato, wheat flour, rice starch, soluble starch and potato starch by simultaneous saccharification and fermentation process.

Although the studies reported above demonstrated that solid-state fermentation can be effective for ethanol production, this kind of fermentation present an inherent difficulty that is the separation of product from solid fermented material. Studies carried out for enzyme recovery demonstrated that depending of experimental condition used in the extraction, significant difference in the results can be obtained by Bender et al. (2008). Several studies are performed to optimize the extraction process of products of commercial interest (Gharekhani et al., 2012; Palmeira et al., 2012).Taking into account that the studies reporting the ethanol production did not focus in the extraction process, then the main objective of this work was to investigate the influence of temperature $\left(30-50^{\circ} \mathrm{C}\right)$, solid to liquid ratio $(0.1-0.4$ $\mathrm{wt} \%)$ and orbital agitation (50-180 rpm) in the recovery of ethanol from sugarcane bagasse at different fermentation conditions of moisture content $(50-80 \%)$ and ethanol amount (5-20 wt $\%$ ).

\section{MATERIAL AND METHODS}

\subsection{Raw Material and Chemicals}

In this work was used sugarcane bagasse obtained in a local distillery, dried at $60^{\circ} \mathrm{C}$ for 72 hours, ground and sieved, collecting the particles that passed through a sieve of 16 mesh. The samples were then stored at room temperature under nitrogen atmosphere prior to the extraction. The ethanol was purchased from Vetec - Brazil with $99.8 \%$ purity. 


\subsection{Experimental Procedure for Ethanol Extraction}

As the objective of the work was to evaluate the influence of different parameters in the extraction of ethanol from sugarcane bagasse after the fermentation, it is important to study the procedure from a raw material that present known amount of ethanol and moisture content. For this reason, it was decided do not carry out the fermentations because is not possible determine the real amount of ethanol produced in the medium due to loss by evaporation and adsorption in the solid material, leading to errors in the determination of recovery efficiency. To overcome this difficulty, it was simulated a fermentation with different moisture content (ranging from 50 to $80 \%$ ) and ethanol amount (5-20 wt\%), obtaining a solid-material with known moisture and ethanol content, making possible the correct determination of recovery efficiency.

For this purpose, $50 \mathrm{~g}$ of dry bagasse were used in each experiment, being corrected the moisture at speci-fied level using deionized water and sterilized at $121^{\circ} \mathrm{C}$ for $20 \mathrm{~min}$ (to simule real fermentation condition). Af-terwards, a determined amount of ethanol was added to the autoclaved solid medium and manually homoge-nized for 10 minutes. The resulting solid material was sealed and maintained under rest for 60 minutes to guarantee a satisfactory adsorption of ethanol into solid bagasse.

After the "simulated fermentation" described above, the solid material was used for ethanol extraction, where a determined amount of deionized water was added aiming to reach the specified solid to liquid ratio, following incubation at determined temperature and orbital agitation. The amount of ethanol recovered was assayed in the supernatant after centrifugation at $4{ }^{\circ} \mathrm{C}$, $15.000 \mathrm{rpm}$ for $15 \mathrm{~min}$. The recovery of ethanol was evaluated at $0,2,4,6,8,10,15,30$ and 60 minutes of extraction.

Different fermentation conditions such as moisture content (50-80\%) and ethanol amount in the fermented bagasse (5-20 wt\%), as well as different extraction con-ditions such as temperature $\left(30-50^{\circ} \mathrm{C}\right)$, orbital agitation $(50-180 \mathrm{rpm})$ and solid to liquid ratio $(0.1-0.4 \mathrm{wt} \%)$. The influence of variables was analyzed considering the methodology of one-factor-one-time.

\subsection{Determination of Ethanol}

After the extractions, an aliquot $(5 \mathrm{~mL})$ of supernatant was used for direct determination of ethanol content using the Alcolyzer Wine M/WE - Wine Analysis Sys-tem (Antoon Par). The results obtained, expressed in terms of ethanol $\% \mathrm{v} / \mathrm{v}$, was converted to ethanol $\mathrm{wt} \%$ and the percent recovery of ethanol determined, taking into account the initial amount added.

\section{RESULTS AND DISCUSSION}

\subsection{Influence of Fermentation Parameters on Recovery of Ethanol}

Table 1 presents the results concerning ethanol re-covering for different moisture contents of fermented sugarcane bagasse. The results are demonstrating that for high moisture content of solids the recovery is more efficient, since $98,9 \%$ of ethanol added to bagasse was recovered when the moisture content was $80 \%$, whereas only $87,2 \%$ was recovered at moisture content of $50 \%$. 
This result is interesting from an industrial viewpoint, since fermentations with high moisture content are preferable for yeast growth, due to the high water activity of solids. In practice, the results obtained here are showing that will be possible to obtain high recovering of ethanol at experimental conditions that present good characteristics for microbial growth. For fixed-bed bioreactors, it is difficult to maintain the moisture content at high level, due to loss by evaporation. However, the use of rotating drum bioreactors can be an effective alternative, due to possibility to replace the water evaporated in the process.

Table 1 - Influence of moisture content on recovering of ethanol from bagasse

\begin{tabular}{ccc}
\hline Run & $\begin{array}{c}\text { Moisture content } \\
(\boldsymbol{\%})\end{array}$ & $\begin{array}{c}\text { Ethanol } \\
\text { recovered }(\%)\end{array}$ \\
\hline 1 & 50 & 87,2 \\
2 & 60 & 90,2 \\
2 & 70 & 98 \\
4 & 80 & 98,9 \\
\hline
\end{tabular}

Fixed variables: $30^{\circ} \mathrm{C}$, solid to liquid ratio of $0.1 \mathrm{wt} \%$, orbital agitation of $100 \mathrm{rpm}$ and initial ethanol amount of $10 \mathrm{wt} \%$.

Other variable important during the recovering the ethanol from fermented sugarcane bagasse is it the amount produced by the microorganism, which can vary greatly in the fermentation, depending of the experimental condition used. In this sense, Table 2 presents the results concerning ethanol recovering at different ethanol amount in the medium. The efficiency of recovering decreased conform the ethanol amount was increasing in the medium. For sake of comparison, the amount recovered when the amount of ethanol added was $5 \mathrm{wt} \%$ was around $20 \%$ higher than adding $20 \mathrm{wt} \%$ was added. The results presented here are indicating that the recovering will be decrease for high production of ethanol in the medium.

Table 2 - Influence of initial amount of ethanol on recovering from bagasse

\begin{tabular}{ccc}
\hline Run & $\begin{array}{c}\text { Ethanol } \\
\text { amount }(\%)\end{array}$ & $\begin{array}{c}\text { Ethanol } \\
\text { recovered }(\%)\end{array}$ \\
\hline 1 & 5 & 84,6 \\
2 & 10 & 77,1 \\
3 & 15 & 95,4 \\
4 & 20 & 71,2 \\
\hline
\end{tabular}

Fixed variables: $30^{\circ} \mathrm{C}$, solid to liquid ratio of $0.1 \mathrm{wt} \%$, orbital agitation of $100 \mathrm{rpm}$ and moisture content of $60 \%$.

\subsection{Influence of Extraction Parameters on Recovery of Ethanol}

Table 3 presents the results that expressing the effect of solid to liquid ratio on ethanol recovering from fermented sugarcane bagasse. Increasing the solid to liquid ratio was verified a significant increase in the amount of ethanol recovered, reaching 94,3\% of recovering for solid to liquid ratio of $0.4 \mathrm{wt} \%$. These results are also attractive on an industrial viewpoint since less water is used during the extraction of ethanol, resulting in more concentrated broth, reducing energy cost in the distillation and in the water treatment. The results presented in Table 3 are showing an advantage of SSF that is the possibility to adjust the amount of water to obtain a concentrated broth (Martins et al. 2011). This point should be taking into account in the analysis of economical 
feasibility of an industrial plant for ethanol production by solid state fermentation.

Table 3 - Influence of solid to liquid ratio on ethanol recovering from bagasse

\begin{tabular}{ccc}
\hline Run & $\begin{array}{c}\text { Solid to liquid } \\
\text { ratio }(\mathbf{w t} \%)\end{array}$ & $\begin{array}{c}\text { Ethanol } \\
\text { recovered }(\boldsymbol{\%})\end{array}$ \\
\hline 1 & 0.1 & 29,9 \\
2 & 0.2 & 57,2 \\
3 & 0.3 & 77,1 \\
4 & 0.4 & 94,3
\end{tabular}

Fixed variables: $30^{\circ} \overline{\mathrm{C}}$, initial ethanol amount of $10 \mathrm{wt} \%$, orbital agitation of $100 \mathrm{rpm}$ and moisture content of $60 \%$.

Table 4 presents the results concerning the influence of temperature in the extraction of ethanol from sugarcane bagasse. In a general way, the temperature did not present significant alterations in the amount of ethanol recovered. The lower temperature evaluated $\left(30^{\circ} \mathrm{C}\right)$ presented the higher ethanol recovering, about $84,7 \%$. This result was possible because ethanol is very soluble in water, in a manner that low amount of water is sufficient to solubilize most of ethanol present. Obviously, the solid matrix is complex and part of ethanol stay adsorbed in internal structure, leading to decrease the recovery efficiency. In practice, the result obtained is desirable, because the extraction can be accomplished industrially at room temperature, without the necessity to use energy to adjust the temperature in the extraction.

Table 4 - Influence of temperature on ethanol recovering from bagasse.

\begin{tabular}{ccc}
\hline Run & Temperature $\left({ }^{\circ} \mathbf{C}\right)$ & $\begin{array}{c}\text { Ethanol } \\
\text { recovered }(\%)\end{array}$ \\
\hline 1 & 30 & 84,7 \\
2 & 40 & 42,3 \\
3 & 50 & 81,0 \\
\hline
\end{tabular}

Fixed variables: initial ethanol amount of $10 \mathrm{wt} \%$, orbital agitation of $100 \mathrm{rpm}$, solid to liquid ratio of $0.3 \mathrm{wt} \%$ and moisture content of $60 \%$.

Table 5 presents the results that expressing the effect of orbital agitation on ethanol recovering from fermented sugarcane bagasse. The results demonstrated that no significant alteration in the recovery efficiency was obtained for orbital agitation ranging from 100 to 180 $\mathrm{rpm}$. However, for orbital agitation of $50 \mathrm{rpm}$, was verified a decreasing in the efficiency around $10 \%$, probably due to evaporation of ethanol during the extraction.

Table 5 - Influence of orbital agitation on ethanol recovering from bagasse.

\begin{tabular}{ccc}
\hline Run & $\begin{array}{c}\text { Orbital agitation } \\
(\mathbf{r p m})\end{array}$ & $\begin{array}{c}\text { Ethanol } \\
\text { recovered }(\%)\end{array}$ \\
\hline 1 & 50 & 87,1 \\
2 & 100 & 99,8 \\
3 & 150 & 99,2 \\
4 & 180 & 97,0 \\
\hline
\end{tabular}

Fixed variables: $30^{\circ} \mathrm{C}$, initial ethanol amount of $10 \mathrm{wt} \%$, orbital agitation of $100 \mathrm{rpm}$, solid to liquid ratio of $0.3 \mathrm{wt} \%$ and moisture content of $60 \%$. 
The better condition for ethanol recovering were the ethanol amount of $10 \mathrm{wt} \%$, solid to liquid ratio of $0.3 \mathrm{wt} \%$, orbital agitation of $100 \mathrm{rpm}$, moisture content of $60 \%$ and temperature of $30^{\circ} \mathrm{C}$, in this condition the ethanol recovering was $99,8 \%$. These results can be improved if the orbital agitation and moisture content were increased, as can be observed in the influence of moisture content (Table 1) and the influence of orbital agitation (Table 5).

\section{CONCLUSIONS}

In this work was demonstrated that the extraction process is an important step during the production of ethanol by solid state fermentation. At the optimized condition at $30^{\circ} \mathrm{C}$, the initial ethanol amount of $10 \mathrm{wt} \%$, orbital agitation of $100 \mathrm{rpm}$ and moisture content of $60 \%$ promoted an ethanol recovery of $99,8 \%$. Even at optimized condition, the recovery of ethanol was not total, demonstrating that is important to define the extraction conditions before the fermentation. Other important results presented here are related to the influence of solid to liquid ratio on the recovering efficiency, where was demonstrated that the amount of water used in the extraction is lesser than that used in traditional liquid fermentation, making possible to obtain a more concentrated broth, saving with water treatment and energy for ethanol concentration.

\section{REFERENCES}

Bender, J.P.; Mazutti, M.A.; Di Luccio, M.; Treichel, H. Extraction of Inulinase obtained by solid state fermentation of sugarcane bagasse by Kluyveromyces marxianus NRRL Y-7571. Appl. Biochem. Biotechnol. 149, 195-203. (2008)

Chu, Q.; Li, X.; Ma, B.; Xu, Y.; Ouyang, J.; Zhu, J.; Yu, S.; Yong, Q. Bioethanol production: An inte-grated process of low substrate loading hydroly-sis-high sugars liquid fermentation and solid state fermentation of enzymatic hydrolysis residue. Bioresour. Technol. 123, 699-702. (2012)

Gharekhani, M.; Ghorbani, M.; Rasoulnejad, S. Microwave-assisted extraction of phenolic and flavonoid compounds from Eucalyptus camaldulensis Dehn leaves as compared with ultrasound-assisted extraction. Latin American Applied Research, 42:305-310. (2012)

International Sugar Organization (ISO). Available in http://www.isosugar.org.

Jain, A.; Morlok, C.K.; Henson, J.M. Comparison of solid-state and submerged-state fermentation for the bioprocessing of switchgrass to ethanol and acetate by Clostridium phytofermentans. Appl. Microbiol. Biotechnol. 97,905-917. (2013)

Kwon, Y.J.; Wang, F.; Liu, C.Z. Deep-bed solid state fermentation of sweet sorghum stalk to ethanol by thermotolerant Issatchenkia orientalis IPE 100. Bioresour. Technol. 102, 1126211265. (2011)

Lin, Y.S.; Lee, W.C.; Duan, K.J.; Lin, Y.H. Ethanol production by simultaneous saccharification and fermentation in rotary drum reactor using ther-motolerant Kluveromyces marxianus. Appl. Energ. 105, 389-394. (2013) 
Luo, L.; Voet, E.; Huppes, G. An energy analysis of ethanol from cellulosic feedstock-corn stover. Renew. Sus. Energ. Rev. 13, 2003-2011. (2009)

Martins, S.; Mussatto, S.I.; Martínez-Avila, G.; Montañez-Saenz, J.; Aguilar, C.N.; Teixeira, J.A. Bioactive phenolic compounds: production and extraction by solid-state fermentation. A review. Biotechnol. Adv. 29(3), 365-73. (2011)

Moukamnerd, C.; Kinooka, M.; Sugiyama, M.; Kaneko, Y.; Boonchird, C.; Harashima, S.; Ninomiya, K.; Shioya, S.; Katakura, Y. Ethanol production from biomass by repetitive solidstate fed-batch fermentation with continuous re-covery of ethanol. Appl. Microbiol. Biotechnol. 88, 87-94. (2010)

Sree, N.K.; Sridhar, M.; Suresh, K.; Rao, L.V. High alcohol production by solid substrate fermenta-tion from starchy substrates using thermotolerant Saccharomyces cerevisiae. Bioprocess Eng. 20, 561-563. (1999)

Palmeira, S. M. V., Gois, L. M. and Souza, L. D. Ex-traction of phenolic compounds from mango peels. Latin American Applied Research, 42:77-81. (2012)

Wang, E.Q.; Li, S.Z.; Tao, L.; Geng, X.; Li, T.C. Modeling of rotating drum bioreactor for anaerobic solid-state fermentation. Appl. Energ. 87, 2839-2845. (2010)

Yu, J.; Xu, Z.; Tan, T. Ethanol production by solid state fermentation of sweet sorghum using thermotolerant yeast strain. Fuel Process. Technol. 89, 1056-1059. (2008) 